\title{
Exhibiting Epistemic Objects
}

\author{
Karin Tybjerg*
}

\begin{abstract}
Scientific and medical collections contain many of what we may call epistemic objects, i.e. objects that have played important roles in the production of knowledge. Drawing on the work of H.-J. Rheinberger on 'epistemic things' and J. Pickstone on 'ways of knowing' this paper considers ways of exhibiting epistemic objects that utilize their knowledge-generating potential and allow them to continue to stimulate curiosity and generate knowledge in the exhibition. The epistemic potential of the objects can then be made to work together with the function of the exhibition as a knowledge-generating set-up in its own right. A focus on epistemic history further allows the cultural and scientific roles of objects of science to be combined in exhibitions. This paper takes its point of departure in the development of displays for the exhibition The Body Collected at Medical Museion in Copenhagen, which shows how anatomical specimens have been used to generate medical knowledge.
\end{abstract}

Keywords: Epistemic objects, objects of knowledge, scientific instruments, anatomical collections, science as process

\section{Introduction: Epistemic Objects in Museums}

Many objects of science found in museums of science and medicine were created in order to generate knowledge. They may be instruments of observation or measurement; they may be the objects of study themselves, such as samples or specimens; or they may be representations or models. Despite their disparity, I will for the purposes of this paper call all these 'epistemic objects': 'epistemic' because of their role in producing knowledge (from Greek episteme 'rational knowledge') and 'objects' in order to align them with other museum objects and point to their materiality. One of the reasons why epistemic objects are exciting to exhibit is that they materialize intersections between nature and our ways of comprehending it, and they demonstrate in a tangible manner that the connections between the world and scientific theories are not simple, but rather deep material entanglements between minds, bodies, instruments and the objects of investigation. The epistemic objects housed in museums are most often not in scientific use, but museums may, I argue, offer possibilities for them to continue to instigate curiosity or even generate knowledge. Display designs that connect to their epistemic context may allow them to do what they were created to do - raise curiosity and create knowledge - and to do so in the context of the museum.

An important point here is that museum displays are themselves material set-ups for generating knowledge. This is part of the historic (and ongoing) role of museums as places where the ordering and display of objects was a form of research (eg Hooper-Greenhill 1992; Pearce 1992; Arnold 2006; Conn 2010). In the disciplines that traditionally worked in museum contexts such as natural history, pathology and anthropology, ordering and displaying collections were core methods of understanding the world, and knowledge was thought to spring directly from creating and studying displays that, for instance, revealed resemblances and differences.

The purpose of this paper is to add to the debate about how to curate scientific objects by suggesting a method that rekindles the relationship between museums, objects and science, and does so in a way that moves beyond the collection sciences. I argue that epistemic objects 
afford particular display possibilities that draw on their potential to generate knowledge. The idea is to combine the knowledge-generating potential of the objects with the knowledgegenerating function of the exhibition in such a way that they support each other. And moreover, to use the way the objects have been accessed scientifically to inform the display design in the exhibition. For instance, light and magnification can be used to display a microscope slide, thus highlighting both the tissue investigated and the culture of investigation it embodies. In this way, epistemic objects are not seen solely as historic or cultural objects, but also as scientific objects, and we can display not just 'science in context', but also 'science in process' and scientific investigation. Epistemic objects thus become material generators of knowledge both cultural and scientific. The method will be unfolded concretely with examples from the development of the exhibition The Body Collected at Medical Museion in Copenhagen, which displays bodily material used for medical research, ranging from preparations of foetuses from the nineteenth century to blood and tissue samples from contemporary biobanks.

But first I will consider some of the challenges to be taken into account when attempting to combine the knowledge-producing potential of the epistemic object with that of the museum display. Both museums and the sciences have changed since the heyday of museum- and collection-based research in the sciences. Starting with museums, the close nexus between museum objects and knowledge making has been loosened in the latter half of the twentieth century. As Conn states in Do Museums Still Need Objects?, the nineteenth century faith in 'the power of objects to convey knowledge, meaning and understanding' is no longer intact (Conn 2010: 5-7). Moreover the role of objects as generators of knowledge has become less central as the focus of museum work has shifted away from research and instruction and towards creating experiences and entertainment, and the contents of exhibitions from taxonomy towards narratives. As part of this process, modern exhibition production and outreach have moved away from collection-management, and the processes of generating knowledge in exhibitions is very often distinct from object-based research in the collections (eg Macdonald 2002; Rader and Cain 2008; Boyle 2014).

Moving onto changes in science since the heyday of museum-based science, the close links between museums and scientific practice only covers a small subset of scientific activity. It was in the collection sciences such as natural history, anatomy and archaeology that scientific knowledge has traditionally been generated in museums (Kohler 2007; Pickstone 2010). Scientific activity has, however, taken place in other sites such as country homes, laboratories, hospitals, observatories and the field. With regard to displaying twentieth and twenty-first century material, science museums are moreover challenged by modern scientific objects being too small, too large or too grey-boxed, to lend themselves to displays; as well as by contemporary science being naturally open ended and full of unknowns (eg Farmelo and Carding 1997; Bennett 2000; Lüthy 2005; Söderqvist et al 2009, Whiteley et al 2017). Lastly, science is in the museum world often divided between being presented as a cultural and historical phenomenon in museums of the history of science and being demonstrated as a timeless collection of theories, practices and phenomena in science centres. Even in the several museums that do straddle history and current science, it is a challenge to combine science as generalized knowledge with more object-based historical accounts (eg Bennett 2000; Boyle 2014).

This is not to say that the challenges of museum practice and scientific practice having moved apart have not been acknowledged and addressed elsewhere. Many attempts have been made in exhibitions to focus on specific objects and to offer museum visitors an experience of the material practices of science and of science in process. The drive to exhibit science in context, science in the making or science in process is widely supported, but the main focus has been on including social and cultural context or acknowledging uncertainty, controversy and political aspects of contemporary science (eg Shapin 1992; Arnold 1996; Farmelo \& Carding 1997; Durant 2004). When it comes to including specific scientific practices in exhibitions, old-school approaches dominate, including replica instruments that can be used by visitors, or dioramas of laboratories or surgical theatres. A more innovative approach tried in recent years has been to set up whole functioning laboratories in exhibitions thus showing science in practice - including the scientists - as an object in itself (eg Meyer 2011).

This paper takes a slightly different approach. Rather than returning to the idea that 
visitors can be like scientists by allowing them to emulate scientific activities, or advocating that whole scientific processes are shifted into exhibitions as complex objects, it suggests that aspects of scientific practice are integrated into the exhibition design. By making the practices of looking and investigating part of the exhibition set-up, the historically close connection between museum display and scientific observation in the natural sciences can be extended into modern scientific practice. In this way, the investigation of the epistemic objects becomes a truly museum-based activity, rather than a scientific activity placed in a museum.

The scientific objects will thus be given a new context - a material set-up - that extends their epistemic life within the exhibition itself. As Sandra Dudley, a strong proponent of attention to the materiality of museum objects, has pointed out, objects are often viewed as 'dead' when removed from their original context and relocated to a museum (Hein 2000: 51). She argues, however, that rather than being de-contextualized, they are in fact re-contextualized (Dudley 2012a: 1-2). This paper concerns how the scientific context and museum re-contextualization can mirror and support each other, both being set-ups where objects generate questions, curiosity and knowledge. The basic aim is having the science-curatorial cake and eating it: both showing historical objects with their beauty and cultural significance, and allowing them to be functional scientific objects. ${ }^{1}$

In sum, the advantage of drawing on the epistemic context of objects in their display is threefold. First it leads to a material engagement with scientific objects; secondly it allows museum visitors to be investigators as well as consumers; and thirdly it provides a way to combine the roles of scientific objects as sources of natural knowledge and cultural objects.

As a theoretical toolbox for considering the epistemic potential of scientific objects in material settings, I draw on Hans-Jörg Rheinberger's concepts of 'epistemic things' and 'experimental systems', which denote the object of study and the framework for studying it respectively (Rheinberger 1997; 2010a; 2010b). Rheinberger writes about the specific case of producing knowledge in twentieth century biological laboratories, but his work will serve more broadly as an inspiration to focus on the material and cultural conditions of knowledgeproduction also in other periods and disciplines. When I use the term 'epistemic object' I thus draw on Rheinberger's 'epistemic things', but generalize it and emphasize that it is both an object of science research and a museum object. In my choice of the term 'object' I am not making a stance vis-à-vis the discussion in so-called thing-theory (eg Brown 2001) where 'objects' are seen as well delineated and 'things' more unbounded. I adhere to common usage, where 'thing' and 'object' are used interchangeably, but where 'object' carries a stronger association to museum objects. ${ }^{2}$ To inform the history of scientific practices over a range of periods, I will draw on Pickstone's idea of 'ways of knowing', which offers a broad and material approach to scientific method that highlights the variation in and historical embeddedness of scientific methods (Pickstone 2010).

Before going more into more detail with regard to the aspects of Rheinberger's and Pickstone's theories that I draw upon, I will briefly situate my approach relative to some of the work in material culture, materialism and science studies that have played important roles in the museological debates at stake. I follow many scholars of material culture in my conviction that material objects have unique potentials for opening up past cultures and scientific practices. As stated in the recent book on object studies at Harvard University museums, Tangible Things, material objects can 'generate excitement, prompt historical curiosity, and produce understanding' (Ulrich et al 2015; also eg Lubar and Kingery 1995 and Prown 1982). Objects can be used as evidence for past culture, they prompt questions that move across disciplines, and they can be used to trace institutional history and social relations (eg Kopytoff 1986; Alberti 2005 and Hallam 2016).

In this article my concern is, however, not only with cultural history and social interactions, but also with a more direct material engagement with objects. Encounters with the basic materiality of objects have received increased attention in recent years. For instance, Sandra Dudley advocates for an engagement with the 'thingness of things' through senses and emotions (Dudley 2010, 2011, 2012), and Adam Bencard argues for a focus on the creation of presence effects in museums, in order to sidestep a dominant focus on narrative and historical context that can draw attention away from the objects themselves (Bencard 2014). My approach strikes a middle path between these groups, combining an attention to the object as evidence for 
past culture with an engagement with the material object, which, crucially, is not so much an immediate sensory encounter as a scientific investigation.

The field of science studies has over the last thirty years reached a related balance between studying science as a social and cultural phenomenon (where the objects of scientific inquiry are often seen as constructed) and studying science as a method for investigating nature (where the objects of scientific inquiry are seen as real and can be discovered), and as a result we may concur with Lorraine Daston in The Biographies of Scientific Objects that 'scientific objects can be simultaneously real and historical' or constructed (Daston 2000: 3). Historically, the field of science studies has moved from a positivist focus on the theories and method of science, through the sociology of scientific knowledge that showed how scientific practice is deeply socially, historically and materially situated (eg Shapin and Schaffer 1985), to laboratory studies, which tracked techno-scientific entanglements between people, nature and technologies (eg Latour and Woolgar 1979 and Pickering 1995). Rheinberger and Pickstone follow on from these developments and their work is particularly suited for my approach to exhibiting epistemic objects, because they combine a sophisticated awareness of the material, historical and cultural embeddeness of science, with an interest in scientific objects, methods and practices.

In the following section I will first outline Rheinberger's and Pickstone's theories and suggest how they provide a useful way of thinking about exhibiting epistemic objects. Then I will outline a number of practical examples drawn from the development of the exhibition The Body Collected at Medical Museion in Copenhagen. Lastly I will discuss some advantages and limitations of this approach to exhibiting epistemic objects.

\section{Rheinberger's Epistemic Things and Pickstone's Ways of Knowing}

Rheinberger introduces the concepts of 'epistemic things' and 'experimental systems' in his Towards a History of Epistemic Things (1997) as part of a detailed study of twentieth century biological lab work. He expands on this work in his An Epistemology of Concrete (2010) setting out his main purpose in the introduction:

... to communicate something of the fascination of scientific things - those organisms, spaces, apparatuses, and techniques that have been colonized and transformed by research, which they in turn have transformed and diversified (2010a: 1).

The driving force here is the fascination of things - the concrete nitty-gritty of science - and the interplay between nature and the research culture that studies it. This is also where museums of science and medicine have a particular role to play. Ideally they can convey exactly the thingness of science and medicine and the intermingling of natural phenomena, technology, concepts, culture and history.

Rheinberger's account centres on the 'experimental system' as the basic unit of research. This includes the entire set-up for experimental investigations and is, Rheinberger notes, also what scientists themselves talk about as the site of their research. The experimental system in Rheinberger does more than testing the correctness of a theory or generating empirical data. In his words the systems are 'not simply experimental devices that generate answers; they are vehicles for materializing questions' (2010: 28 - my emphasis). Similarly, exhibitions with epistemic objects should not just supply answers. Rather they should materialize further questioning and investigation of objects and their contexts.

Rheinberger distinguishes two elements in the experimental system. The first is the 'epistemic thing', which is the object under investigation, e.g. a physical structure, chemical reaction or biological function. The epistemic thing is characterized by an 'irreducible vagueness' and embodies what we do not yet know. When it is investigated through experimentation, the experiment does not simply uncover features that are already there. Rather it articulates the epistemic thing by manipulating it. The notion of epistemic things being open-ended and 'always in the process of being materially defined' is further developed by Karin Knorr Cetina, who also emphasizes that knowledge cultures and 'the machinery of knowing' are essential components for understanding what science is (Knorr Cetina 2001: 181 and 1999: 1-2). 
In order to manipulate the epistemic thing the scientist needs the second element of the experimental system, namely the 'technical objects' (Rheinberger 1997: 28). The 'technical objects' consist of both the technology and culture surrounding the scientific process. They include instruments as well as theoretical concepts, institutional culture, traditions and skills of scientists and technicians. The 'technical objects' are basically the machinery of science in its widest sense.

Working with the experimental system and generating knowledge thus consists in a complex interplay between the epistemic thing and the technical objects. The material and the conceptual, nature and culture, cannot be separated. Rather, the epistemic things and the technical objects form and manipulate each other: 'Phenomenon and instrument, object and experience, concept and method are all engaged in an ongoing process of mutual instruction' (Rheinberger 2010a: 31). The experiment thus constitutes a specific material culture that unites the natural and the social, the practical and the theoretical (Rheinberger 1997: 19). In this view the development of science is a deeply historical and cultural process, but not an arbitrary or purely socially determined one. Science takes shape and changes over time, rooted in culture, but bounded by nature. The scientific process is thus not separate from a surrounding culture. It is culture.

Considering now how to draw on Rheinberger's account of experiments for curating and designing exhibitions, we may view the exhibition as another layer of investigation adding to the process of scientific experimentation. The way visitors and curators investigate objects through curatorial strategies and exhibition design can be compared to how scientists manipulate and study objects in experimental systems. The exhibition is then itself a 'technical set-up' that generates knowledge, resonating with the early purpose of museums. This also reflects newer 'experiments' in museology as described by Basu and Macdonald, who have drawn inspiration for exhibition-making from experimentation: 'knowledge generating procedure[s]' that '[make visible] the processes by which scientific knowledge was established' (2007: 2 and 4). When exhibition design draws on the way in which nature intersects with our instruments, viewing the exhibition comes to mirror the process of scientific investigation. The ideal scenario is that epistemic objects are allowed to continue the production of knowledge in the exhibition knowledge that concerns both natural phenomena and scientific culture because the epistemic object combines both. Hence, while the objects that are part of museum collections may have lost the uncertainty and potential of further unfolding in their purely scientific context, they may retain this potential when it comes to an exploration of the full epistemic culture of science: the interaction between the object of exploration and the material and historical conditions in which it was investigated.

Rheinberger states himself that his account of science may be useful in an exhibition context. In the passage quoted below he is mainly concerned with imaging strategies, but the emphasis on 'making scientific thinking tangible' is at the heart of my approach to displaying the epistemic processes in museums.

I think it makes sense to analyze epistemic imaging strategies such as the ones described above and think about whether their peculiar character can be exploited for making meaning in exhibitions. ... One question then becomes: how can the visualization modes of compression and dilation, of enhancement and of schematization be fruitfully modified for making science and scientific thinking tangible. This is the first point. The second point concerns the close interconnectedness among instrumental technologies, the scientific object, and the corresponding forms of visualization. ... This connectedness as well is something that ought to be considered and thought about in exhibition practice. Particular instruments, the corresponding objects, and their visualizations belong to each other and thus can - and should - be made to bear on each other (Rheinberger 2010b: 22).

In the second part of the quote he emphasizes that all parts of the experimental process should be presented in the exhibition. I would like to take this a step further and incorporate the process in the exhibition design to allow the visitor to be part of investigating the exhibited objects.

Rheinberger's work concerns mainly experiments in twentieth century modern bioscience. The focus on using exhibitions to explore epistemic objects may, however, be broadened to include other scientific disciplines and periods. For this purpose we may draw on another 
account of knowledge-production in science, namely John Pickstone's Ways of Knowing. Pickstone writes a broad history of science, technology and medicine, where he moves away from the notion of one scientific method. Instead he identifies a number of so-called 'ways of knowing' - methods for generating knowledge - which change in relative importance throughout history. While each way of knowing is predominant in a particular period and typical of particular disciplines, several can co-exist. The particular ways of knowing Pickstone lists - 'worldreadings', 'natural history', 'analysis', 'experimentation' and 'technoscience' - are different modes of generating knowledge from objects where 'natural history' for instance is concerned with collecting and categorizing objects, 'analysis' with taking them apart, and 'experimenting' with controlling phenomena and creating novelties (Pickstone 2010: 3).

The ways of knowing are not seen as exclusive to science, but bridge between technical scientific worlds and everyday worlds, and Pickstone describes them as forms of work related to ways of making and mending (Pickstone 2010: 5). These two aspects - the connection to everyday practices and the materiality of knowledge processes - make Pickstone's 'ways of knowing' a useful tool for thinking about curating.

In the context of exhibiting epistemic objects, 'ways of knowing' can be viewed not just as a 'way of making' (as in Pickstone), but can also be deployed as 'ways of displaying'. The actions of categorizing and splitting up can be applied as ways to display the objects at stake that usefully mirror the way they have been manipulated scientifically. Moreover, the display can draw on the material way in which the relevant ways of knowing were applied in scientific work: how categorization, analysis and experimentation worked materially, how new aspects of the objects were rendered visible or measurable, and thereby also how they might be accessed by the museum visitor.

Rheinberger and Pickstone offer two very different accounts of scientific practice: Rheinberger a painstaking analysis of a particular site of scientific knowledge production; Pickstone a long history of methods in a broad selection of disciplines. But both insist on the historicity and materiality of scientific practice, and their concepts of 'epistemic things', 'technical objects' and 'ways of knowing' together offer a flexible theoretical tool kit for exhibiting scientific processes that adds to the more tried and tested strategies of showing scientific objects alongside their social and cultural histories.

In my approach, I maintain a broader definition of epistemic objects than Rheinberger, who defines them as the objects under investigation. Rheinberger does, however, also describe how an object may move back and forth between being the 'epistemic thing' and being part of the 'technical set-up' (Rheinberger 2010a: 218-19). For instance, a piece of instrumentation may be subjected to investigation if it is thought to be a source of unusual results, and an organism may be investigated in its own right first and later be used as a model organism, i.e. an instrument, for investigating something else. I therefore believe that instrumentation could also be exhibited with attention to epistemic processes, even if instruments are not 'epistemic things' in Rheinberger's strict sense. I moreover draw on Pickstone to look beyond Rheinberger's focus on experimental practice to additionally consider the unfolding of epistemic objects within collections, microscopy and even data-driven sciences.

\section{Exhibiting Epistemic Objects in Practice}

To recapitulate, the method of exhibiting epistemic objects suggested here is to draw on the material, epistemic context in which scientific objects have generated knowledge in the design of exhibition displays. In this way, the processes of investigating the object in its original scientific context and in the exhibition support each other. The exhibition thus becomes another site - or another 'experimental system' - where a material object is unfolded, and both the object itself and the way of knowing are presented in the exhibition. But how might this be done in practice?

The ideas presented here - of trying to integrate the process of generating knowledge into the displays - were developed as part of curating the exhibition The Body Collected at Medical Museion in Copenhagen. The exhibition opened in May 2015 and shows how parts of the human body have been collected and investigated in order to generate medical knowledge. The Body Collected follows a continuous history of collections from the pathological collections of the nineteenth century, over microscope slide archives showing tissue structures, to twentyfirst century biobank collections of blood and tissue samples (Tybjerg 2015 \& 2016). It displays 
a broad range of medical specimens such as preparations of embryos, organs, microscope slides and blood samples.

The exhibition mainly presents the material from the point of view of medicine rather than from the social, contextual or political views points that favour stories of patients, institutions or practitioners. ${ }^{3}$ The exhibition does not, however, aim to show the materials in the way in which medicine presents itself in textbooks, anatomical collections or professional histories. We curated the objects to highlight continuities and differences in epistemic practice and the exhibition shows the craft involved and the particularity and materiality of the processes of generating knowledge from body parts. This is culture, but it is scientific culture in the way that Rheinberger and Pickstone describe it rather than what is normally understood as cultural context.

The Body Collected lent itself to developing strategies for exhibiting the epistemic properties of objects, because it is concerned exactly with the production of knowledge. It is also interesting for this topic because it covers a long historical period and the objects span a variety of relations between scientific practice and the museum. In fact, the original idea to draw on epistemic practices when designing the displays came from noticing the contrasts between the ways in which the older and newer specimens had been studied. While the foetuses and organs preserved in glass jars could be exhibited in a similar fashion to the way they were investigated scientifically - namely in vitrines - the slides and the blood samples could not be exhibited in their full laboratory or biobank glory. They were not 'at home' in a museum and their surrounding technologies were not easily displayed because, like much lab equipment, they were large, incomprehensible grey boxes, and expensive to get hold of.

With a curatorial focus on production of knowledge over a long time span we did not, however, want to be defeated by this asymmetry between the old and the new objects. Instead we sought to generalize the idea that the display mirrored the way the specimens were accessed scientifically. So rather than treating the display technologies as a neutral background that happen to have similarities with the way the early collections were accessed, we wanted the displays to show changing ways of investigating the human body. The specimens were to be shown in exhibition designs that reflected the epistemic context at the same time as highlighting the materiality of the objects.

The specimen preparations are also a particularly interesting group of epistemic objects when it comes to displaying the intersection between nature and the instruments and methods with which we investigate it. They embody both the object investigated (pathological organs, tissue structures, genetic markers) and the material manipulations that enable these investigations (dissecting, colouring, growing, separating, amplifying). All specimens are both nature and artefact. Even the historical, anatomical specimens that appear most natural and simply excised from the body are the products of cultural practices of collection and the crafts of dissection and preservation (Alberti 2008 and 2011; Hermannstädter et al 2015). The more recent specimens are hard to recognize as natural; they hardly look like they derive from a human body. In this way, both lend themselves to displays that combine attention to the different material objects and the accompanying methods of investigation; and such displays can bring out how the object is partly constructed by the method of investigation. Indeed, Rheinberger writes that preparations - anatomical specimens, microscope slides, chromatographic plates - hold a special potential for communicating research, exactly because the object of study is saved or stabilized in a form suitable for investigation.

[D]eposited in their diverse configurations layer upon layer is a record of the modern research process. [The research process] can, moreover, be very precisely and vividly visualized in them; thus they make it possible to communicate to the public the idea that science is research - a comprehensive, far-reaching, manifold cultural process (Rheinberger 2010b: 243).

In the same way as the specimens reveal the layers inside the physical body, they are simultaneously layers in the epistemic journey of the investigation of the body, where the body has been continually configured in new ways to make it accessible and to show deeper structures. By mirroring scientific investigation in the display, the exhibition allows visitors to see how this investigation shapes and creates its objects of study in a way that is ance cultural, scientific and historically embedded. 
In the following I will discuss specific set-ups developed for The Body Collected at Medical Museion. Not all of them became part of the final exhibition, but they constitute steps towards developing the method and bringing epistemic qualities into the display of scientific objects.

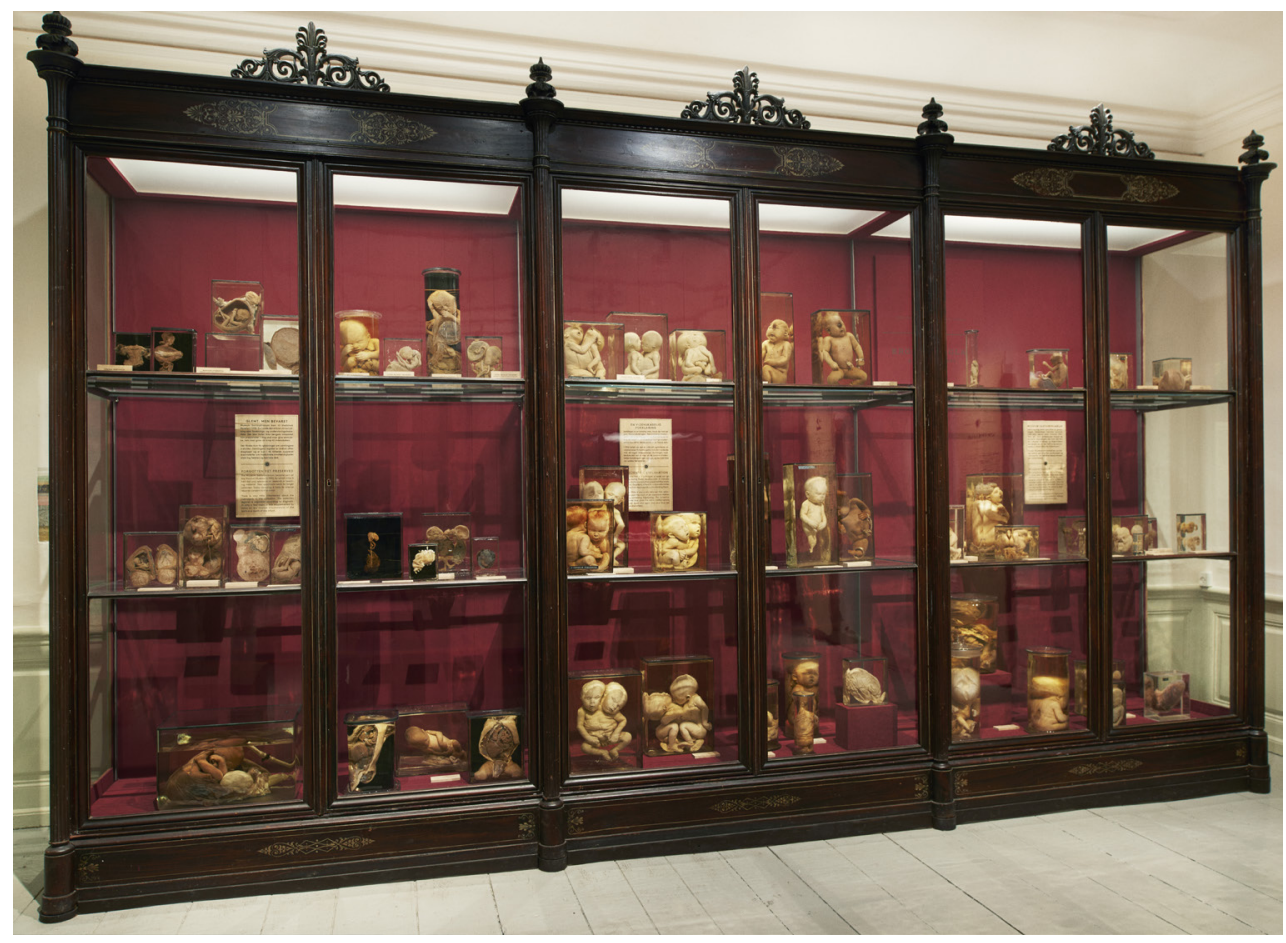

Figure 1. The Saxtorphean Collection of infants and fetuses is displayed in a historic vitrine that mirrors the way it has been used scientifically to categorize disease and malformations. From The Body Collected at Medical Museion (2015- ); photography by Nicolai Howalt.

\section{Collection and dissection}

Some scientific objects are intended to be viewed in museums. This is the case for many natural history specimens and for the preparations of diseased organs from pathological collections that form the starting point of The Body Collected. Such objects were originally presented in glass vitrines and the systematization of objects was a way of systematizing the world, a way of knowing in Pickstone's sense (2010). This makes it deceptively straightforward to display the way the objects were used to generate knowledge by simply recreating historical vitrine displays. Objects can thus be viewed in their historical context while also displaying how they were used. Such displays are found in many anatomical and pathological collections, for instance the handsome exhibitions at Museum Vrolik in Amsterdam and Hunterian in London. In Medical Museion the display of the so-called Saxtorphean Collection of infants and fetuses also draws on historical categorizations from the catalogue of the collection and is even housed in a re-fitted historical exhibition case (figure 1).

In some instances, however, the use of historical cases and displays becomes a way to historicize the material and point out its difference from modern scientific practices. This can for instance be seen at the Museum Vrolik or the Anatomical Museum at the University of Leiden, where parts of the collections are placed to the side in historical cabinets representing outdated theories, while other parts of the collection are treated as scientific material and shown in supposedly 'timeless' glass display cases. Other historical displays make the whole collection into a single object, as with the awe inspiring 'crystal gallery' at The Hunterian (currently under redevelopment). In contrast, the intention in The Body Collected is not to emphasize 


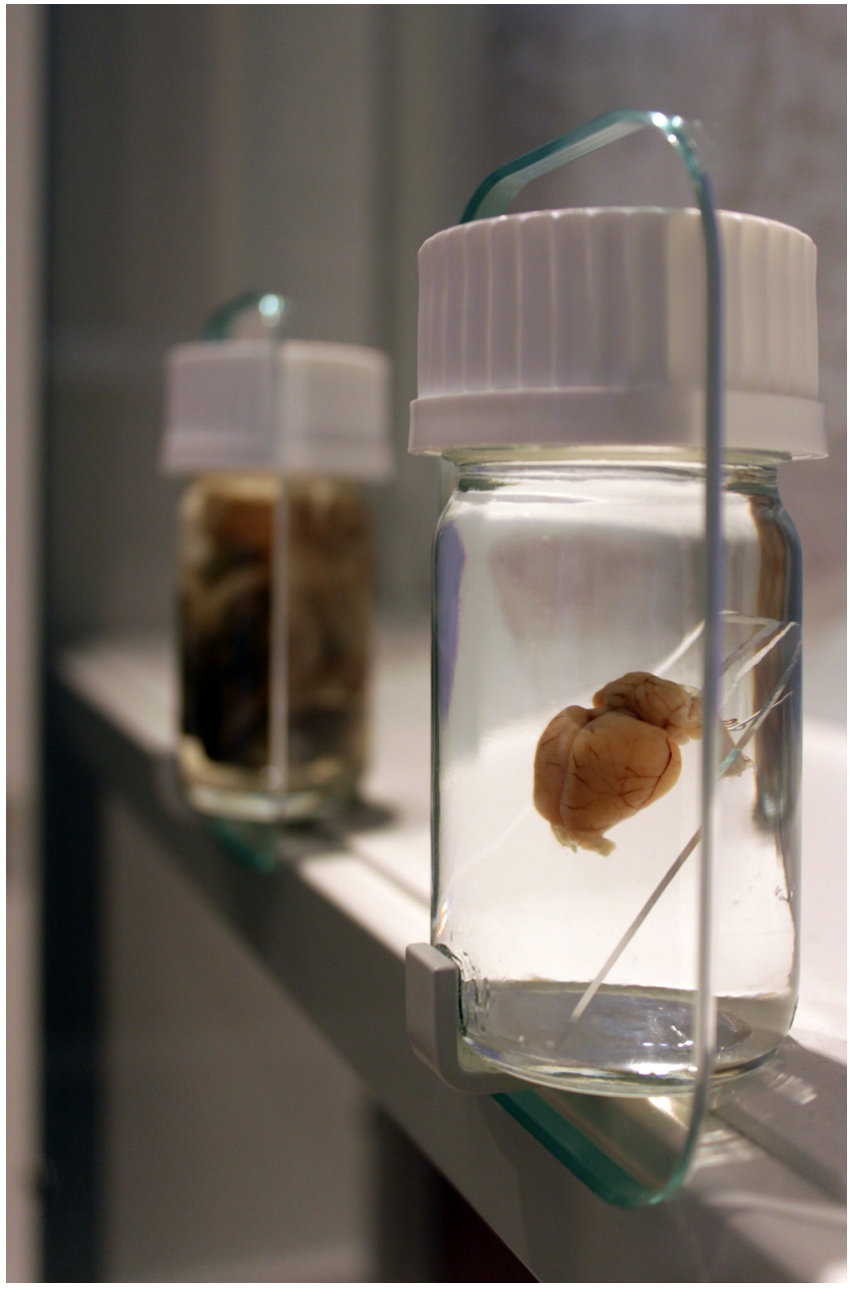

Figure 2. Case where the glass or 'skin' of the exhibition case is cut open to show the specimen. The display mirrors how dissection uncovers the body by cutting through layers of skin and tissue. From Obesity: What is the Problem?, Medical Museion (2012-2017); photography by Ane Pilegaard. historical remoteness or to present the scientific process as a historicized object, but to create displays that bring out the epistemic potential of the objects. While the historical display itself in The Body Collected does not dramatically differ from displays in other collections, it is mirrored by the displays of later collections of slides and biobank samples, thus emphasizing the continuous importance of the practice of collecting and the natureartifact hybridity of bodily preparations.

For the display of these early collections, we also considered displaying the process of generating knowledge by putting the technology of museum categorization on display. The idea was to cut through a historical exhibition case and cover the cut side with glass; to display the technique of collecting and categorizing as well as the objects. The design was discarded partly on practical and aesthetic grounds, but also because it would create a layer that took the viewer further away from the objects rather than closer to investigating them. We wanted the epistemic objects to remain at the center rather than making the scientific method the main object of the exhibition. ${ }^{4}$

An important part of the epistemic investigation of the preparations in anatomical and pathological collections is that they are dissected to display particular aspects of diseases or anatomy. This splitting up of the body into its constitutive parts is in Pickstone associated with analysis - understanding the whole through the parts. In the museum display this process may be mirrored by 'dissecting' and opening layers in the display cases (on the anatomical conception of the body as layered, see Hallam 2016: 298). Cutting through the glass 'skin' of the vitrine mirrors the surgical method of removing the outer layers of the body to free the structures inside (see figure 2 and Pilegaard 2015). Instead of using an exhibition text to explain the scientific process of analysis through splitting up, it can be expressed through a display design that highlights the way that the objects themselves generate knowledge and thereby emphasizes attention to the objects themselves. 


\section{Microscopy}

With the introduction of the microscope in medicine and biology, deeper structures in the body became accessible for investigation. Tissues were cut into thin slices, stained to bring out the micro-structures of interest, and studied using light and magnification in microscopes. The structures of the body could thus be viewed through processes of enhancement, lighting and enlargement.

Microscope slides have been essential in medicine and the biosciences, but have tended to live quiet lives in museums. Generally slides are not deemed to make attractive displays, because they are small and hard to tell apart. They do, however, hold exciting possibilities for showing the body as an epistemic object, because they represent an exemplary combination of the object under investigation with the work necessary to make it observable. As Löwy writes on the microscope slides as material and epistemic objects: They "are at the same time "things in themselves" (samples of biological material), "preparations" (artifacts) and "representations" (stabilized images of the studied objects)' (Löwy 2011: 3). This aspect is lost in the many exhibitions that show only the microscopes themselves and enlarged images.

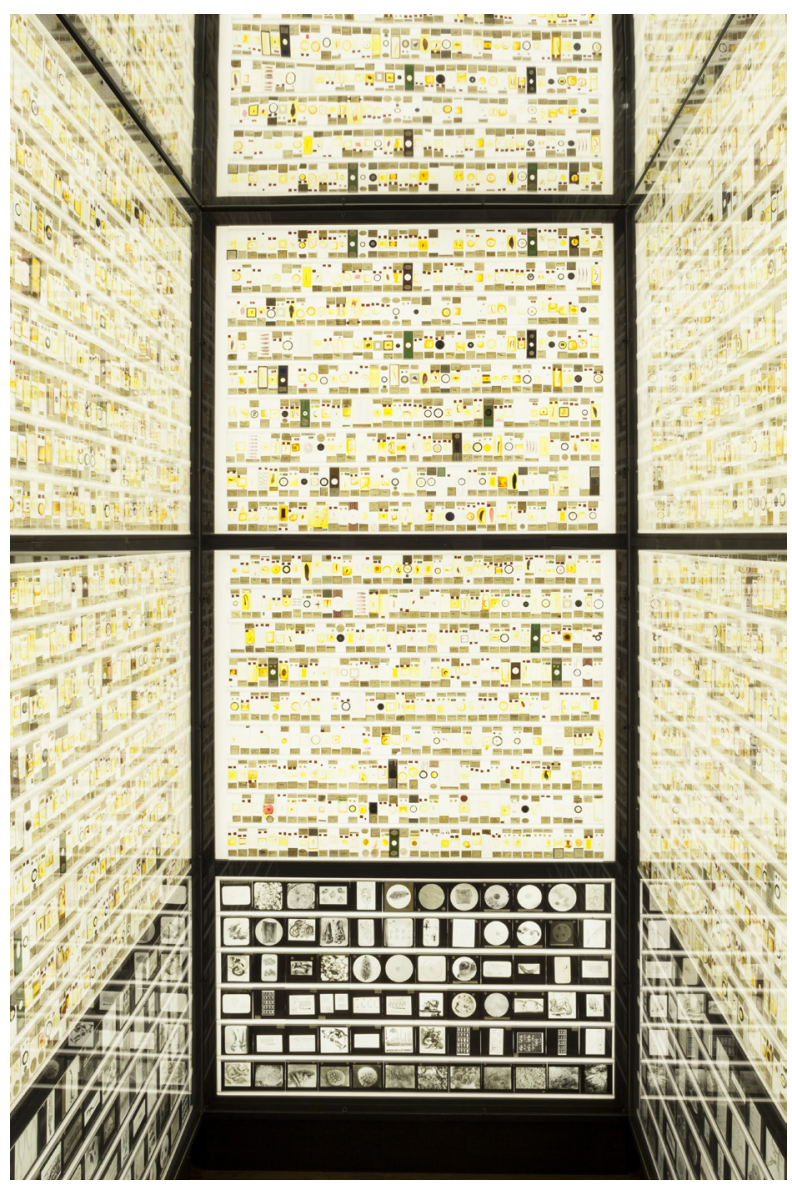

Figure 3. A collection of microscope slides is displayed to show both the practice of collecting and the use of light to bring out the structure and details. From Micrarium, (C) UCL Grant Museum of Zoology (2013- ); photography by Matt Clayton.
Bydrawing on the processes that make tissue structures visible - e.g., enhancement, light, enlargement, focus - in the exhibition display, the epistemic process can be highlighted together with the material objects themselves. The visitor is allowed to observe the slides more closely, but through an exhibition design rather than simply allowing visitors to look through microscopes themselves.

An example of such a display, which inspired the work with The Body Collected, is the Micrarium at Grants Museum of Zoology where a collection of slides is exhibited in a tiny room covered floor to ceiling in backlit slides (see figure 3). ${ }^{5}$ This display beautifully captures both the collection as a source of knowledge and the way the slides were accessed through light. When visitors compare slides and study the details and multitude of forms, they explore both the micro-world that was the scientific object of knowledge and the scientific way of generating knowledge. Importantly, the display does not match the scientific processes exactly, but draws on them in its design in a way that allows new unfoldings of the epistemic objects of the slides.

A simple display technique that is used in The Body Collected consists of a large magnifying glass that can be moved across the displayed microscopic slides to 


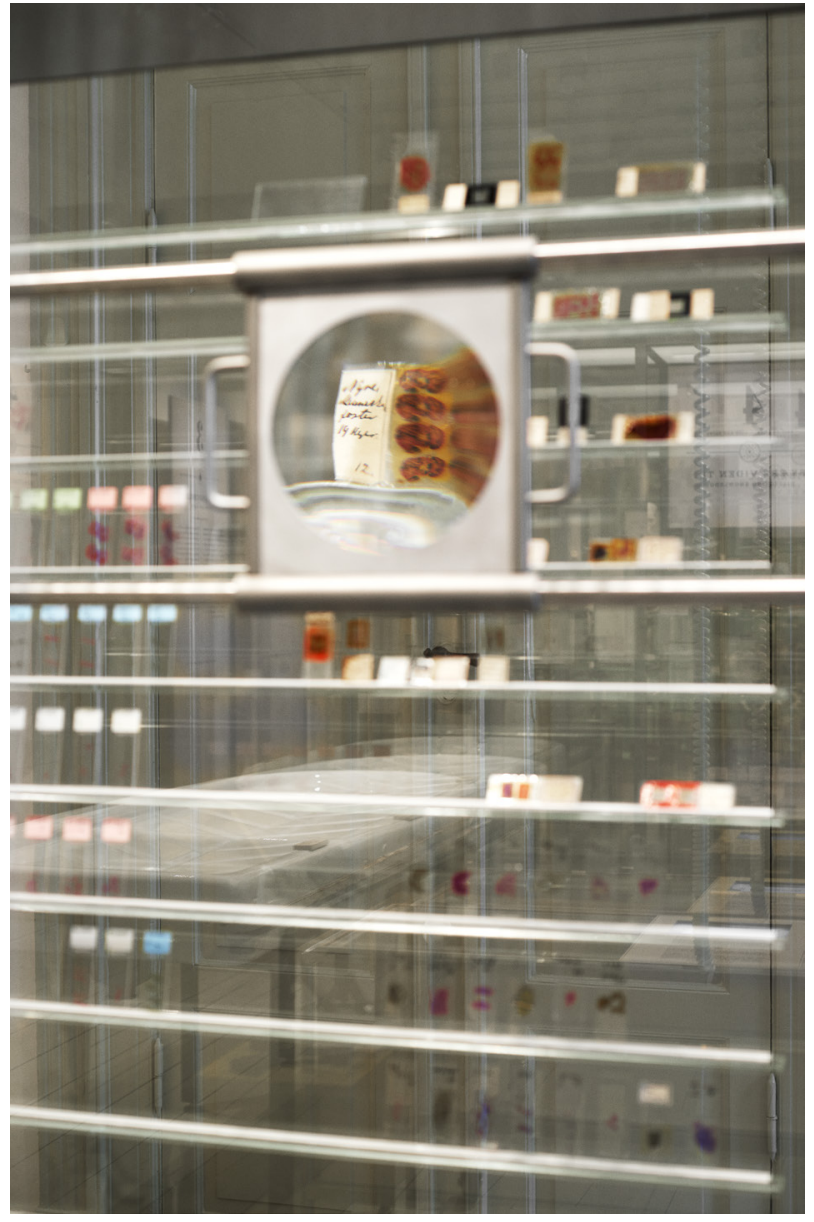

Figure 4. In a simple display, microscope slides are enlarged by a moving magnifying glass to highlight the epistemic importance of both collecting and moving below the field of vision. From The Body Collected at Medical Museion (2015- ); photography by Nicolai Howalt. magnify the details of the stained tissue.Again, the magnifying glass does not exactly copy the scientific practices of using microscopes, but displays both the collection and the comparison of slides together with the important point that the study of the body has moved below the field of vision.

Another set-up which was not included in the exhibition, but which we are developing for future display, is a projection of a microscopic image on the wall. When the museum visitor approaches the image, it will be enlarged and come into focus (figure 4). In this way the body of the exhibition visitor engages with the image from the slide in a way that echoes the way the slide was originally accessed by the doctor or scientist. It moves the scientific study into the size range of the visitors, inviting them to use their body and senses to explore the slide. By engaging the body, it may capture a little of the embodied excitement of microscope research. The electron microscopist Susan Hockfield wrote of her experience with an electron microscope,

...you can start at a low magnification... Then by increasing magnification, the very fine details of organelles within the cells emerge. [When] I began in electron microscopy ... the electron beam was projected through the sample under study onto a screen, which had to be viewed in the dark. So the experience of using an electron microscope, in a darkened room ... felt very much as though you, yourself, were 'in the microscope.' I would spend hours in the microscope, scanning tissue, with a wonderful feeling of being inside the specimen. (Hockfield 2008: 222)

Here, Hockfield has simultaneously a sense of being in the microscope and in the specimen. The display may capture this sense by using the body both to enlarge and to step into the image. The machinery of investigation and the object of investigation become one, showing the intertwined nature of epistemic things and technical systems.

\section{Biobanking and laboratory analysis}

As laid out above, the scientific processes of recent science and medicine can be hard to exhibit. The technologies surrounding the objects of scientific enquiry have grown over time and frequently 


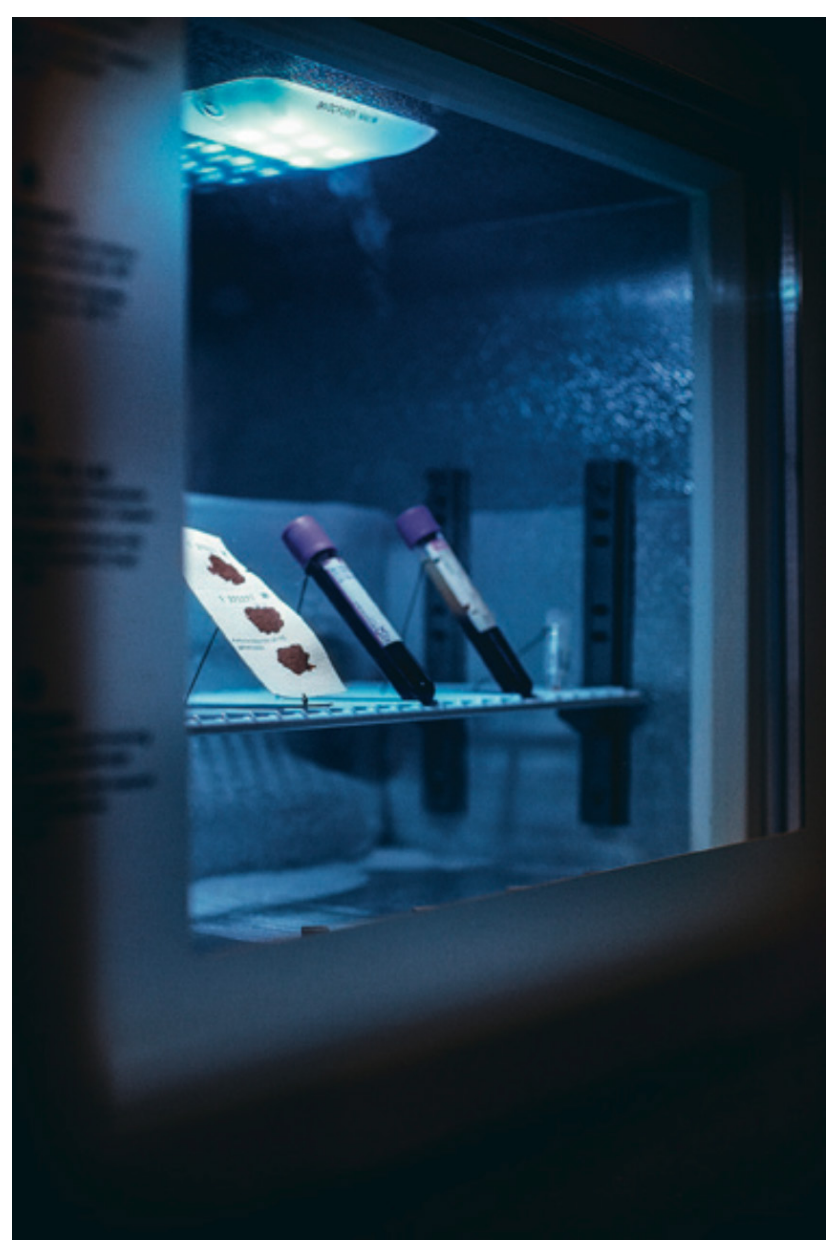

Figure 5. Display of blood samples in a biobank freezer made into an exhibition case to show that human material is still collected though it is accessed with different technologies than the display cabinet. From The Body Collected at Medical Museion (2015-); photography by Nicolai Howalt.

xhibition. The displays highlighted this contemporary collection practice w at the end of the this contemporary collection practice within biomedicine scientific by using a biobank freezer as the exhibition case (figure 5). Even if freezers are not transparent and the categorization is done via biochemical rather than visual means, the display demonstrated an epistemic practice that cuts across contemporary and historical science because using the freezer as a display case mirrors traditional vitrines and their organization of knowledge into categories.

A more oblique and abstract way of using elements of scientific practice in displays is illustrated by the installation Genomic Enlightenment also at Medical Museion (figure 6). Here a set of gene chips from a scientific research project is hung up from the ceiling from light emitting cables. The chips are hung 'en masse' in a wave, visually and materially suggesting the scientific project of aggregating a vast array of data in order to detect patterns. The title and the use of light in the installation links the modern scientific 'big data'-practices to enlightenment science with its faith in finding underlying order in collections of things or data. 


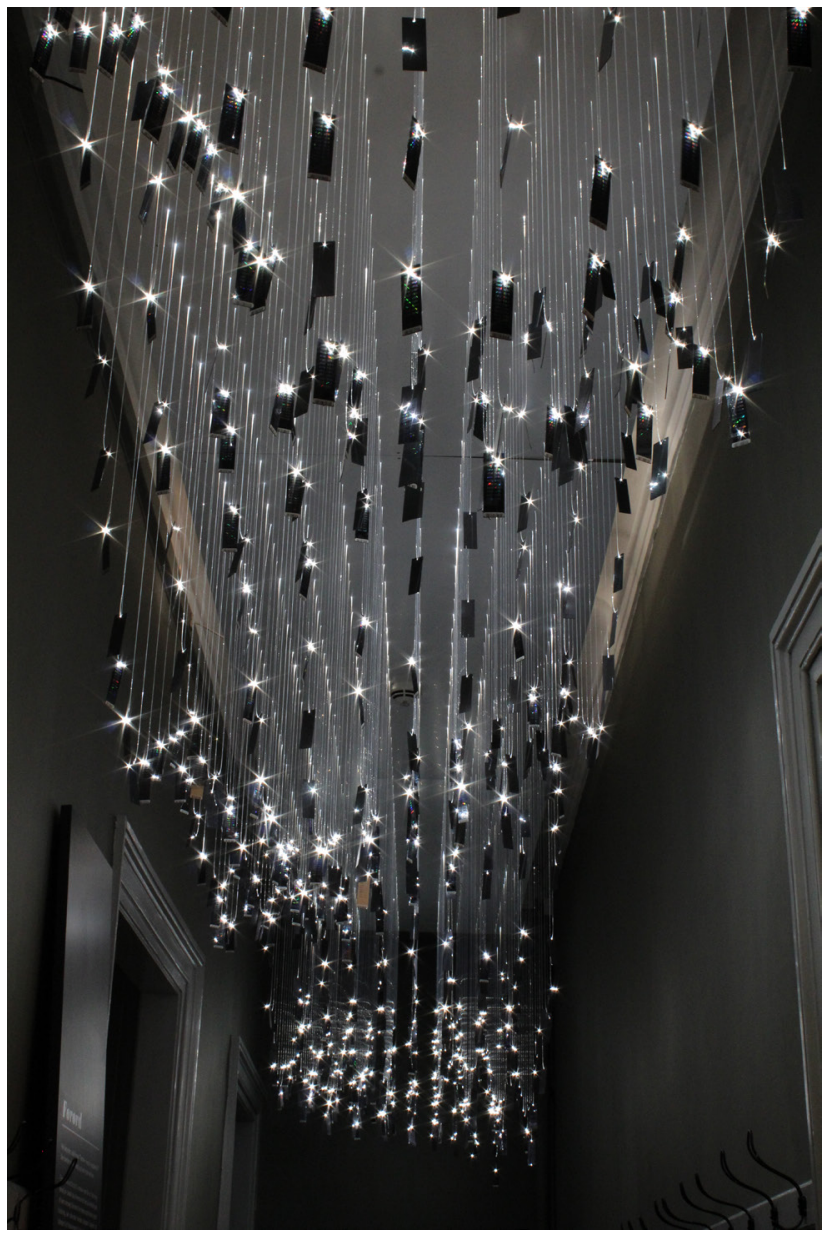

Conclusion

Objects in museums used to play an epistemic role in several sciences. Visitors, students and practising scientists understood natural history or anatomy by preparing, viewing, and examining displays of objects. But as science moved out of the museums, displays of objects lost their epistemic connection to the sciences. Exhibitions on science and medicine have since faced the challenge of how to create knowledge in museums once we move beyond the contexts where the museum was a fundamental tool for research.

The solution, however, is not to give up on the possibility of mediating the scientific roles of objects in the museum. While we cannot make museums a place for the majority of scientists to work, I believe we can do more than show collections and laboratories as delineated objects in museum exhibition. The particular method advocated here is to design displays that allow the material unfolding of scientific experimentation or practice to continue in the exhibition. This method is also a further step in

Figure 6. An installation of a set of so-called genechips used for an exploration of gene variations shows the continued importance of the collection and comparison in modern genetics. From Genomic Enlightenment at Medical Museion (2011- ); photography by Jacob Kjærgaard.

the direction of lessening the gap between science centres aiming to transmit generalized scientific knowledge and museums of the history of science emphasizing social and cultural context of scientific practice.

The goal is ambitious and the method has some natural limitations. First, the displays cannot capture the full specificity of the material conditions of scientific work, emphasized as crucial in Rheinberger's account. It may even mislead as the displays do not copy methods of investigation, but only mirror them in ways that make sense as exhibition displays. I would argue, however, that despite the risk of misrepresentation, there are advantages to avoiding the direct copying or mimicry of scientific practice. A copy can never be true, while a set-up that captures key elements of scientific investigation may offer a strong sense of the phenomenology of doing science that works with the premises of the museum exhibition.

A second limiting factor is that the method may have a narrow range of applicability. It is not clear that the method will work as well with other scientific objects such as instrument collections. Preparations of the body are, as pointed out by Rheinberger (2010a, see above), a special case because they contain both the object of science and the way it is investigated. 
Other objects in museums of science are cultural historical objects that do not lend themselves to be exhibited as knowledge generating. Moreover, the method is stronger when the main curatorial concern is epistemic. The epistemic role of scientific objects is, however, so central to their use, that unless an exhibition is purely cultural historical, it will inevitably play a role. The opposite question is whether the method might be completely general and any object may be exhibited in such a way that the display mirrors how it is used to gain knowledge, defined in the broadest sense. An ethnographic object may, for instance, be displayed in a manner mirroring a particular ritual. This may be fruitful, but I will not pursue this line further. Here, I will simply maintain that the nexus between the museum, the material object and scientific research is strong enough to warrant special attention.

To summarize the advantages of considering epistemic history in display design, we may return to the three advantages of the approach sketched in the introduction: it focuses on the material objects themselves, it encourages investigation in the museum without being explicitly didactic, and it shows the objects of science as both objects of culture and nature.

First, by combining the epistemic potential of the objects and of the exhibition, attention is directed back onto the material objects - the distinguishing feature of museums. It allows the exhibition of epistemic objects to operate in the overlap between museum research and scientific investigation, by generalizing the connection between display design and the scientific way of looking at collections typical of nineteenth century anatomy and natural history. The ideal would be that the objects of scientific enquiry and the associated instruments continued to produce new knowledge in the exhibition. This is ambitious, as a museum visit cannot foster the close material connectedness of scientists to their instrumentation and objects of study. On a smaller scale, however, the approach leads to displays that encourage a close attention to the material and craft-like aspects of scientific knowledge and culture. This is demonstrated clearly by the case of the Micrarium, which creates new explorations of the microscope slides as well giving an impression of the power of collecting.

Second, by making the medium or methods of scientific investigation - collecting, dissection, light, transparency, enlargement, amplification and technological mediation - into display strategies, the visitor is not directly asked to explore in a didactic way, but is led to the objects themselves in ways that underscore scientific exploration. In this way, the content of the exhibition is played out in the design combining the act of studying the exhibition with partaking in the epistemic processes and history of the sciences.

Finally - and related to the previous points - the scientifically mediated exploration of epistemic objects yields one of the best possibilities for combining understanding of both the scientific processes and the historical and cultural context of science, because they are conjoined in the specific objects. The specificity of material objects demonstrates the important point that although scientific insights are granted general applicability, they are the products of specific, material investigations into specific epistemic objects. Epistemic objects are, as both Rheinberger and Pickstone emphasize, very much hybrids of culture and nature, and attention can fruitfully be given to methods of display that show both together. Often the wider implications or incomprehensible aspects of science are mediated through art, through science didactics, or historicized, but here I advocate for a middle ground. Not pure science, history or art, but inventive, creative displays that materialize the scientific process.

There was once faith in museums as places where displayed objects could generate knowledge in their visitors. Justified doubt in this preposition has been one factor in the move towards displays where museum objects play very minor roles. My point here is to try to keep faith in objects, but to develop display practices that mediate the intertwining of object and practice, nature and culture, and science and museums.

Received: 7 February 2017

Finally accepted: 5 January 2018

\section{Notes}

1 Gauvin (2016) argues for display of scientific function as opposed to aesthetics, but this paper argues the two may be combined. Bennett (2002) emphasizes that exhibitions should not just communicate the science, but also the ambiguity inherent in the material objects. 
2 For the use of 'things' as something broader and less restricted than 'objects' see eg Bennett (2010) and Brown (2001), who takes 'things' to be less ordered and more sensuous than objects. For a pragmatic approach that uses the terms interchangeably, see Tangible Things by Ulrich et al. (2015). In my account I emphasize, like Daston (2000), that scientific objects can be simultaneously real and constructed.

3 While the main track of the exhibition is from a medical point of view it does include a discrete track with accounts of some of the individuals whose body parts are exhibited.

4 This approach can also produce exciting displays such as Making Nature: How we See Animals at Wellcome Collection, which shows the 'Ordering', 'Displaying', 'Observing' and 'Making' of nature.

5 Jack Ashby, 'Tiny Praise for the Micrarium at the Museums + Heritage Awards', 2014, UCL Museums and Collections Blog, http://blogs.ucl.ac.uk/museums/2014/05/15/tiny-praisefor-the-micrarium-at-the-museums-heritage-awards/\#more-34614, accessed 25 January 2017.

\section{References}

Ackermann, S., Kremer, R. and Miniaiti, M. (eds) (2014) Scientific Instruments on Display, Leiden: Brill.

Alberti, S.J.M.M. (2005) 'Objects and the Museum’, Isis 96, 559-71.

(2008) 'Constructing Nature Behind Glass', Museum and Society 9, 73-97.

(2011) Morbid Curiosities: Medical Museums in Nineteenth-century Britain, Oxford: Oxford University Press.

Arnold, K. (1996) 'Presenting Science as a Product or a Process: Museums and the Making of Science' in S. Pearce (ed) Exploring Science in Museums, 57-77, London: Athlone.

(2006) Cabinets for the Curious - Looking back at Early English Museums, Aldershot: Ashgate.

Basu, P. and Macdonald, S. (2007) 'Introduction: Experiments in Exhibition' in P. Basu and S. Macdonald (eds) Exhibition Experiments, 1-24, Oxford: Blackwell Publishing.

Bencard, A. (2014) 'Presence in the Museum: On Metonymies, Discontinuity and History Without Stories', Museum \& Society 12 (1), 29-43.

Bennett, J. (2010) Vibrant Matter: A Political Ecology of Things, Durham/London: Duke University Press.

Bennett, J. (2000) 'Beyond Understanding: Curatorship and Access in Science Museums' in S. Lindqvist, M. Hedin and U. Larsson (eds) Museums of Modern Science, 55-60, Canton (Massachusetts): Science History Publications.

Boyle, A. (2014) "'Not for their Beauty": Instruments and Narratives at the Science Museum, London' in S. Ackermann, R. Kremer and M. Miniaiti (eds) Scientific Instruments on Display, 37-60, Leiden: Brill.

Brown, B. (2001). 'Thing Theory' in B. Brown (ed.), Things, a special issue of Critical Inquiry 28 (1), 1-22. 
Conn, S. (2010) Do Museums still Need Objects?, Philadelphia: University of Pennsylvania Press.

Daston, L. (ed.) (2000) The Biographies of Scientific Objects, Chicago: University of Chicago Press.

Dudley, S.H. (2010) 'Museum Materialities: Objects, Sense and Feeling', in, S.H. Dudley (ed.) Museum Materialities: Objects, Engagements, Interpretations, 1-43, London and New York: Routledge.

(2011) 'Introduction: Museums and Things' in S. Dudley, A. J. Barnes, J. Binnie, J. Petrov and J. Walklate (eds) The Thing about Museums: Objects and Experience, Representation and Contestation, 1-11, London/New York: Routledge.

(2012) 'Encountering a Chinese Horse: Engaging with the Thingness of Things', in S.H. Dudley (ed.) Museum Objects: Experiencing the Properties of Things, 1-15, London and New York: Routledge.

Durant, J. (2004) 'The Challenge and the Opportunity of Presenting "Unfinished Science"' in D. Chittenden, G. Farmelo and B. V. Lewenstein (eds) Creating Connections: Museums and the Public Understanding of Current Research, 47-61, Walnut Creek: AltaMira Press.

Farmelo, G. and Carding, J. (1997) Here and Now: Contemporary Science and Technology in Museums and Science Centres, London: Science Museum.

Gauvin, J.F. (2016) 'Functionless: Science Museums and the Display of "Pure Objects”', Science Museum Group Journal. DOI: http://dx.doi.org/10.15180/160506.

Hallam, E. (2016) Anatomy Museum: Death and the Body Displayed, Chicago: University of Chicago Press.

Hein, H. (2000) The Museum in Transition: A Philosophical Perspective, Washington: Smithsonian Books.

Hermannstädter, A., Heumann, I., Pannhorst, K. and Lessing, J. (2015) Wissensdinge Geschichten aus dem Naturkundemuseum, Berlin: Nicolaische Verlagshandlung $\mathrm{GmbH}$.

Hockfield, S. (2008) in S. Turkle, (ed.) Falling for Science: Objects in Mind, Cambridge (Massachusetts): MIT Press.

Hooper-Greenhill, E. (1992) Museums and the Shaping of Knowledge, London/New York: Routledge.

Knorr Cetina, K. (1999) Epistemic Cultures: How the Sciences Make Knowledge, Cambridge (Massachusetts): Harvard University Press.

(2001) 'Objectual Practice' in T.R. Schatzki, K. Knorr-Cetina and E. von Savigny (eds) The Practice Turn in Contemporary Theory, 184-197, New York/London: Routledge.

Kohler, R.E. (2007) 'Finders, Keepers: Collecting Sciences and Collecting Practice', History of Science 45, 428-54.

Kopytoff, I. (1986) 'The Cultural Biography of Things', in Arjun Appadurai (ed.) The Social Life of Things: Commodities in Cultural Perspective, 64-91, Cambridge: Cambridge University Press. 
Latour B. and Woolgar, S. (1979) Laboratory Life, Beverly Hills: Sage Publications.

Löwy, I. (ed.) (2011) Microscopic Slides: Reassessing a Neglected Historical Ressource, Berlin: MPIWG.

Lubar, S. and Kingery, W. D (eds) (1993) History from Things - Essays on Material Culture, Washington: Smithsonian Books.

Lüthy, C. (2005) 'Museum Spaces and Spaces of Science. Reflections on the Explanatory Possibilities of History of Science Collections', Nuncius 20 (2), 415-29.

Macdonald, S. (2002) Behind the Scenes at the Science Museum, Oxford/New York: Berg.

Meyer, M. (2011) 'Researchers on Display: Moving the Laboratory into the Museum', Museum Management and Curatorship 26 (3), 261-72. DOI: 10.1080/09647775.2011.585800.

Pearce, S.M. (1992) Museums, Objects, and Collections: A Cultural Study, Leicester: Leicester University Press.

Pickering, A. (1995) The Mangle of Practice: Time, Agency and Science in the Making, Chicago: The University of Chicago Press.

Pickstone, J.V. (2010) Ways of Knowing. A New History of Science, Technology and Medicine, Manchester: Manchester University Press.

Pilegaard, A. (2015) 'Epistemic Mutations: Material Object Engagement in Exhibition Making' in: EKSIG 2015: Tangible Means: Experiential Knowledge of Materials conference proceedings, 106-117, http://experientialknowledge.org.uk/ proceedings_2015_files/EKSIG2015_Proceedings.pdf

Prown, J.D. (1982) 'Mind in Matter: An Introduction to Material Culture, Theory and Method', Winterthur Portfolio 17 (1), 1-19.

Rader K.A. and Cain, V.E.M. (2008) 'From natural history to science: Display and the transformation of American museums of science and nature', Museum and Society 6 (2), 152-171.

Rheinberger, H.-J. (1997) Toward a History of Epistemic Things: Synthesizing Proteins in the Test Tube, Stanford: Stanford University Press.

(2010a) An Epistemology of the Concrete. Twentieth-Century Histories of Life, Durham: Duke University Press.

(2010b) 'Making Visible. Visualizations in the Sciences - and in Exhibitions?' in S. LehmannBrauns, C. Sichau, H. Trischler (eds), The Exhibition as Product and Generator of Scholarship, Preprint 399, Berlin: Max-Planck-Institut für Wissenschaftsgeschichte .

Schnalke, T. (2009) 'Tracing Life: the history, concept and goals of the permanent exhibition in the Berlin Museum of Medical History at Charité', Journal of History of Medicine 21 (1), 117-140.

Shapin, S. (1992) 'Why the public ought to understand science-in-the-making', Public Understanding of Science 1, 27-30.

Shapin, S and Schaffer, S. (1985) Leviathan and the Airpump: Object Lessons from Art and Science, Princeton: Princeton University Press. 
Söderqvist, T., Mordhorst, C. and Bencard, A. (2009) 'Between meaning culture and presence effects: contemporary biomedical objects as a challenge to museums', Studies in History and Philosophy of Biological and Biomedical Sciences 40, 431438.

Strasser, B. J. 'Collecting Nature: Practices, Styles and Narratives', Osiris 27 (1), 303-40.

Tybjerg, K. (2015) 'From Bottled Babies to Biobanks: Anatomical Collections in the 21st Century' in R. Knoeff \& R. Zweijnenberg (eds) The Fate of Anatomical Collections, 263-78, London/New York: Routledge.

(ed) (2016) The Body Collected. Copenhagen: Medical Museion.

Whiteley, L., Tybjerg, K., Pedersen, B. V., Bencard, A. and Arnold, K. (2017) ‘Exhibiting health and medicine as culture', Public Health Panorama 3 (1), 59-68.

Ulrich, L. T.,'Carter,’S. A., Gaskell,„l., Schechner,’S and van Gerbig, S. (2015) Tangible Things: Making History Through Objects, Oxford: Oxford University Press.

\section{Acknowledgements}

The ideas of this paper were developed in the process of curating The Body Collected at Medical Museion, University of Copenhagen. I am very grateful for inspiration and discussions with colleagues and collaborators, in particular Adam Bencard, Ane Pilegaard and Sandra Dudley, as well as for helpful comments from the anonymous referees.

* Karin Tybjerg is an Associate Professor at Medical Museion, University of Copenhagen a position that combines research and curatorial work. She curated The Body Collected and has published on anatomical collections, history of astronomy and museology. She holds a PhD in History and Philosophy of Science from University of Cambridge and has previously been Keeper of Ethnography and Modern History at the National Museum of Denmark.

Address:

Medical Museion

Fredericiagade 18

DK-1810 Copenhagen $\mathrm{K}$

Denmark

Email address:

Karin.tybjerg@sund.ku.dk 